\title{
Are sedatives and hypnotics associated with increased suicide risk of suicide in the elderly? Anders Carlsten ${ }^{* \dagger 1}$ and Margda Waern ${ }^{\dagger 2}$
}

\author{
Address: ${ }^{1}$ Social Medicine, Department of Public Health and Community Medicine, Sahlgrenska Academy at Gothenburg University and Nordic \\ School of Public Health, Gothenburg, Sweden and ${ }^{2}$ Department of psychiatry and neurochemistry, Sahlgrenska Academy at Gothenburg \\ University, Gothenburg, Sweden \\ Email: Anders Carlsten* - anders.carlsten@apoteket.se; Margda Waern - margda.waern@neuro.gu.se \\ * Corresponding author †Equal contributors
}

Published: 4 June 2009

BMC Geriatrics 2009, 9:20 doi:10.1/86/147|-23/8-9-20
Received: 27 October 2008

Accepted: 4 June 2009

This article is available from: http://www.biomedcentral.com/I47I-23/8/9/20

(C) 2009 Carlsten and Waern; licensee BioMed Central Ltd.

This is an Open Access article distributed under the terms of the Creative Commons Attribution License (http://creativecommons.org/licenses/by/2.0), which permits unrestricted use, distribution, and reproduction in any medium, provided the original work is properly cited.

\begin{abstract}
Background: While antidepressant-induced suicidality is a concern in younger age groups, there is mounting evidence that these drugs may reduce suicidality in the elderly. Regarding a possible association between other types of psychoactive drugs and suicide, results are inconclusive. Sedatives and hypnotics are widely prescribed to elderly persons with symptoms of depression, anxiety, and sleep disturbance. The aim of this case-control study was to determine whether specific types of psychoactive drugs were associated with suicide risk in late life, after controlling for appropriate indications.
\end{abstract}

Methods: The study area included the city of Gothenburg and two adjacent counties (total 65+ population 210703 at the start of the study). A case controlled study of elderly $(65+)$ suicides was performed and close informants for 85 suicide cases ( 46 men, 39 women mean age 75 years) were interviewed by a psychiatrist. A population based comparison group $(n=153)$ was created and interviewed face-to-face. Primary care and psychiatric records were reviewed for both suicide cases and comparison subjects. All available information was used to determine past-month mental disorders in accordance with DSM-IV.

Results: Antidepressants, antipsychotics, sedatives and hypnotics were associated with increased suicide risk in the crude analysis. After adjustment for affective and anxiety disorders neither antidepressants in general nor SSRIs showed an association with suicide. Antipsychotics had no association with suicide after adjustment for psychotic disorders. Sedative treatment was associated with an almost fourteen-fold increase of suicide risk in the crude analyses and remained an independent risk factor for suicide even after adjustment for any DSM-IV disorder. Having a current prescription for a hypnotic was associated with a four-fold increase in suicide risk in the adjusted model.

Conclusion: Sedatives and hypnotics were both associated with increased risk for suicide after adjustment for appropriate indications. Given the extremely high prescription rates, a careful evaluation of the suicide risk should always precede prescribing a sedative or hypnotic to an elderly individual. 


\section{Background}

The use of psychotropic drugs among the elderly is high [1-3] and health risks associated with these drugs are a topic of public health concern. Increased risk for fall accidents $[4,5]$, adverse drug reactions [6], drug related morbidity [7] and unfavourable interactions with other medication [8] have been emphasized in the literature. While the induction of suicidality is a concern in younger age groups [9], there is increasing evidence that antidepressants may be beneficial in the prevention of suicide late in life [10-15]. Regarding a possible association between other types of psychoactive drugs (sedatives, hypnotics, antipsychotics) and suicide, results are inconclusive [16-18]. Sedatives and hypnotics are widely prescribed to elderly persons with symptoms of depression, anxiety, and sleep disturbance. They are regularly detected in post-mortem analyses of elderly suicide victims, and often implicated in lethal overdoses in Sweden [19].

The elderly consume more psychotropics than any other age group in Sweden [20]. There have been substantial changes in the sales of psychotropic drugs to persons aged 65 and above over the last fifteen years. While sales of antipsychotics (Figure 1a) and sedatives (Figure 1b) decreased by almost $50 \%$ during this time period, sales of hypnotics remained extremely high (Figure 1c). Sales rates are particularly high in the older elderly, with Defined Daily Dosages (DDD)/1000 inhabitants and day as high as 165 in women and 120 in men (Figure 1c). SSRIs were introduced in Sweden in 1990 and antidepressant sales have seen a near five-fold increase since that time (Figure 1d.)

Given the high psychotropic prescription rates and the high suicide rates in this age group it would be appropriate to examine whether different types of psychotropic drugs are associated with increased suicide risk. When testing for a possible association, it is important to rule out confounding by indication. However, studies that include detailed evaluation of psychiatric symptoms in elderly suicides and population-based controls are lacking. The aim of the current study was thus to determine whether different types of psychotropic drugs were associated with increased risk of suicide in persons aged 65 years and above after adjustment for appropriate indications.

\section{Methods}

One hundred consecutive cases of suicide among persons aged 65 years and above who underwent necropsy at the Gothenburg Institute of Forensic Medicine were reviewed. Close informants for 85 suicide cases (46 men, 39 women, mean age 75 years) accepted to participate in an interview with a psychiatrist (MW). We have previously shown that the study cases were representative of all sui- cides among persons age 65 and above in the catchment area during the study period; antidepressants and/or lithium were detected at post-mortem analysis in $38 \%$ of the study cases and $40 \%$ of the 100 suicides (65+) evaluated at the Forensic Institute during the study period [21]. The study area included the city of Gothenburg and two adjacent counties (total 65+ population 210703 at the start of the study).

In order to create a population comparison group, two people with the same sex, year of birth and zip code as each suicide case were randomly selected from the tax register. If a potential comparison person declined participation, another was invited (up to eight per case). In all, 240 people were invited to take part in the study and 153 participated ( 84 men, 69 women). Comparison subjects were interviewed face-to-face, using the same questionnaire. Primary care and psychiatric records were reviewed for suicide cases and comparison subjects. All available information was used to determine past-month mental disorders in accordance with DSM-IV [21].

Ongoing prescriptions were classified according to the Anatomical Therapeutic Chemical (ATC) classification [22]. For the purpose of this study the following drugs were classified as sedatives: diazepam, alprazolam, buspirone, hydroxizine and dixyrazine. These were classified as hypnotics: flunitrazepam, nitrazepam, zopiclone, zolpidem, oxazepam, levomepromazine, propiomazine and alimemazine. Dixyrazine is a neuroleptic, but here classified as sedative in accordance with its main clinical use. Levomepromazine, a neuroleptic and alimemazin, an antihistamine were both included in the hypnotic group because they are prescribed in Sweden to elderly with sleep disturbance.

\section{Ethics}

The study was approved by the Ethics Committee at the Faculty of Medicine, Gothenburg University.

\section{Statistics}

Crude odds ratios for suicide were calculated for the different classes of psychotropic drugs with bivariate logistic regression. In a second set of analyses, odds ratios were adjusted for age, sex and appropriate indications (see footnote Table 1) using multivariate logistic regression.

\section{Results}

Psychotropic drugs were widely prescribed to the suicide cases and all drug types were associated with suicide in the unadjusted analyses (Table 1). Antidepressants were prescribed to $40 \%$ of the cases at the time of the suicide. Antidepressant medication was associated with a ten-fold increase in suicide risk in the initial analysis. However, after adjustment for affective disorders and anxiety disor- 

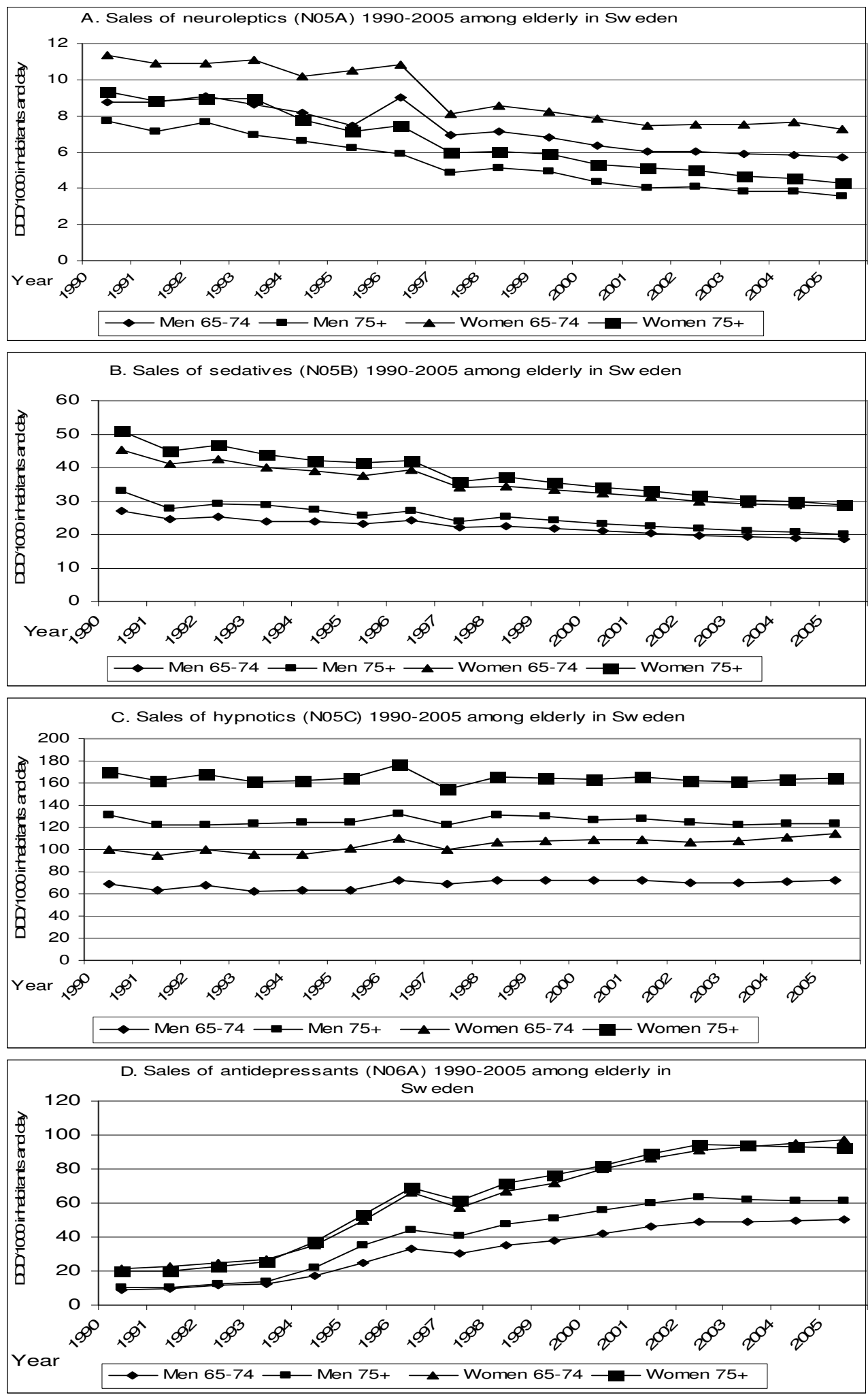

Figure I

The sales of psychotropic drugs 1990-2005 among elderly in Sweden. 
Table I: Psychotropic drugs prescribed to elderly suicide cases $(n=85)$ and population controls $(N=I 53)$. Odds ratios and $95 \%$ confidence intervals.

\begin{tabular}{lcccc}
\hline Type of drug prescribed & $\begin{array}{c}\text { Cases } \\
\mathbf{n}(\%)\end{array}$ & $\begin{array}{c}\text { Controls } \\
\mathbf{n}(\%)\end{array}$ & OR(95\% CI) $^{\mathbf{a}}$ & $\mathbf{O R}^{(95 \% ~ C I)} \mathbf{b}^{\mathbf{b}}$ \\
\hline Any antidepressant & $34(40)$ & $9(6)$ & $10.7(4.8-23.8)$ & $0.9(0.2-3.2)$ \\
$\quad$ SSRls & $23(27)$ & $8(5)$ & $6.7(2.9-15.9)$ & $0.8(0.2-2.9)$ \\
Antipsychotics & $9(11)$ & $4(3)$ & $4.4(1.3-14.8)$ & $2.7(0.8-10.1)$ \\
Sedatives & $31(36)$ & $6(4)$ & $14.1(5.6-35.6)$ & $4.4(1.3-15.2)$ \\
Hypnotics & $48(56)$ & $16(10)$ & $10.8(5.4-21.5)$ & $4.2(1.6-11.0)$ \\
\hline
\end{tabular}

a Unadjusted

b Adjusted for age, sex and indication. Antidepressants adjusted for affective and anxiety disorders, antipsychotics adjusted for psychotic disorders, sedatives and hypnotics adjusted for any DSM IV Axis I disorder.

ders, neither antidepressants in general nor SSRIs in particular showed an association with suicide.

Antipsychotics were prescribed to one tenth of the suicide group at the time of death. Only $3 \%$ of those in the comparison group had a prescription for an antipsychotic. Antipsychotic medication was associated with increased suicide risk in the initial analyses, but the association did not remain after adjustment for psychotic disorder.

While sedative use was uncommon among persons in the control group, over a third of the suicide cases were prescribed sedatives at the time of death. A prescription for a sedative was associated with an almost twelve-fold increase of suicide risk after adjustment for anxiety disorders (OR 11.8 C.I. 4.6-30.6). As sedatives may be indicated for anxious elderly with other types of mental disorder (depression, psychosis) a second model was constructed which adjusted for any DSM IV disorder. Sedative treatment remained an independent four-fold risk factor for suicide even in the fully adjusted model (Table 1).

Hypnotics were the most widely prescribed drug type in both cases and controls. Half of the suicide cases had a prescription for a hypnotic at the time of the suicide. Hypnotics were prescribed to one tenth of the comparison group. A prescription for a hypnotic drug was associated with a ten-fold increase in suicide risk in the crude analysis. As sleep disturbance may occur in most psychiatric disorders, the final model was adjusted for any Axis I disorder. Having a current hypnotic prescription was associated with a four-fold increase in suicide risk in this adjusted model.

As interactions between psychoactive drugs and alcohol may trigger impulsive behaviour, we wanted to test whether suicide victims who used sedatives/hypnotics were more likely to have a positive post-mortem test for alcohol. For hypnotic users, 11 out of 47 cases had a positive test for alcohol compared to 14 out of 35 for nonusers $(\mathrm{p}=0.146$, Fisher's exact test). For sedative users, 8 out of 31 had positive registration for alcohol compared to 17 out of 51 for non-users ( $p=0.622$, Fisher's exact test).

\section{Discussion}

We found a four-fold increased suicide risk among elderly using sedatives and/or hypnotics after adjustment for appropriate indications. A recent Canadian register-based study showed a similar odds ratio [23], but it should be noted that those results pertained specifically to use of benzodiazepines, and diagnoses were based on physicians claims files. Our finding is at odds with that of Barak and colleagues [18] who compared rates of benzodiazepine prescription in elderly patients with major depression who did/did not attempt suicide. The proportion with benzodiazepines was larger in the group that did not attempt suicide. Several methodological differences may help to explain the conflicting results. First, the outcome variable in the study by Barak and colleagues was attempted rather than completed suicide. Second, controls in that study were psychiatric patients; our study employed face-to-face interviews with individuals randomly selected from the underlying population. Third, the proportion of women was greater in the Barak study. Women tend to have higher rates of sedative use than men, and men higher suicide rates than women.

One possible explanation for the observed increase in suicide risk associated with sedatives and hypnotics in our study may be that these drugs trigger aggressive behaviour [24]. Further, interactions between benzodiazepines and alcohol may intensify impulsive tendencies, thereby increasing risk of suicide. We have previously reported that $29 \%$ of the suicide cases in the current study had a positive post-mortem test for alcohol [25]. However, proportions a positive post-mortem test for alcohol were similar in suicide cases both with and without sedatives/ hypnotics, indicating that interaction with alcohol cannot fully explain the observed increase in risk. Another partial explanation might be that persons with prescriptions for these drugs have ready access to a suicide method. Availa- 
bility of suicide methods increases suicide risk [26]. The current study design does not allow us to tease out the contribution of availability of suicide means on suicide risk. Suicide methods vary widely in different cultural settings. It would be of interest to test whether sedatives and hypnotics are associated with increased late-life suicide risk even in settings where other suicide methods, such as hanging or shooting are more common.

The finding that sedatives and hypnotics were associated with increased suicide risk does not in itself imply causality. It is possible that these drugs are merely markers for some other factor related to suicide risk, such as somatic illness, functional disability, alcohol use disorder, interpersonal problems, lack of social network [27] and sleep disturbance [28]. Persons with these problems might be more likely to seek health care and perhaps more likely to receive prescriptions for psychotropic drugs.

To the best of our knowledge, this is the first study to examine use of psychotropic drugs in elderly suicides and matched population controls who have been subjected to a detailed evaluation of psychiatric symptoms. We did not find support for the hypothesis that SSRIs increase suicide risk in the elderly, after controlling for indication. Taken together with previous observations from ecological studies [10-13], from retrospective analyses of patient records [18] and register studies [14], this is important information for the clinician, who might be less inclined to prescribe antidepressants in the aftermath of the "black box warning" that was issued regarding risks in adolescents [29].

\section{Strengths and limitations}

A major strength of this study was the inclusion of detailed psychopathological data which eliminated issues of confounding by indication. Study cases were representative of all suicides in the catchment area [21]. Major limitations include small numbers and the fact that diagnoses of the suicide victims are based on data accrued by proxy interviews. However, there is evidence that suicide studies based on proxy interviews with next of kin (so-called "psychological autopsies") provide reliable diagnoses [30]. Further, medical records were readily available for cases and controls, and these were authored by physicians who were "blind" to the suicide outcome. Another methodological concern was that the participation rate for the comparison subjects was lower (64\%) than that of the suicide informants (85\%). Potential comparison persons with mental illness and psychotropic drug treatment might be less likely to participate, which would result in inflated odds ratios.

\section{Implications for the clinician}

While antidepressant prescription was not an independent predictor of suicide risk, it is noteworthy that $40 \%$ of the elderly cases committed suicide despite prescribed treatment for affective illness. Treatment failure cannot be ascribed to lack of adherence to antidepressants, as we have previously shown that antidepressants were detected at post-mortem screening to a large degree [21]. As pointed out by Szanto and colleagues [31], there is a need for intensive treatment and follow-up of the depressed and suicidal elderly. In the present study, sedatives and hypnotics were related to increased risk for late life suicide. Clinicians need to be aware of this as these drugs are widely prescribed to the elderly. A careful evaluation of the suicide risk should be carried out when an elderly person presents with symptoms of anxiety and sleep disturbance.

\section{Conclusion}

In conclusion sedatives and hypnotics were both associated with increased risk for suicide after adjustment for appropriate indications. Given the extremely high prescription rates, a careful evaluation of the suicide risk should always precede prescribing a sedative or hypnotic to an elderly individual.

\section{Competing interests}

The authors declare that they have no competing interests.

\section{Authors' contributions}

MW was responsible for the design of the study and the study interviews. AC was responsible for collection and analysis of the pharmacological data and performed the statistical analyses. Both AC and MW prepared the manuscript. Both authors read and approved the final manuscript.

\section{Acknowledgements}

Supported by grants from the Swedish Foundation for Health Care Science and Allergy Research (V98 226), the Swedish Council for Social Research (F0042 and 0914) and the Swedish Research Council (K2004-2IPD-15I02OIA).

\section{References}

I. NOMESCO: Medicines Consumption in the Nordic Countries 1999-2003. NOMESCO, Copenhagen; 2004.

2. Linjakumpu T, Hartikainen S, Klaukka T, Koponen H, Kivelä SL, Isoaho R: Psychotropics among the home-dwelling - elderly increasing trend. Int J Geriatr Psychiatry 2002, 17:874-883.

3. Linjakumpu TA, Hartikainen SA, Klaukka TJ, Koponen HJ, Hakko HH, Viilo KM, Haapea M, Kivelä SL, Isoaho RE: Sedative drug use in home-dwelling elderly. Ann Pharmacother 2004, 38:2017-2022.

4. Panneman MJ, Goettsch WG, Kramarz P, Herings RM: The costs of benzodiazepine associated hospital treated fall injuries in the EU: a Pharmo study. Drugs Aging 2003, 20:833-839.

5. Leipzig RM, Cumming RG, Tinetti ME: Drugs and falls in older people: a systematic review and metaanalysis: I. Psychotropic drugs. J Am Geriatr Soc 1999, 47:30-39.

6. Routledge PA, O'Mahony MS, Woodhouse KW: Adverse drug reactions in elderly patients. Br J Clin Pharmaco 2004, 57:121-126. 
7. Klarin I, Wimo A, Fastbom J: The association of inappropriate drug use with hospitalisation and mortality: a population based study of the very old. Drugs Aging 2005, 22:69-82.

8. Bjorkman IK, Fastbom J, Schmidt IK, Bernsten CB: Pharmaceutical Care of the Elderly in Europe Research (PEER) Group. Drugdrug interactions in the elderly. Ann Pharmacother 2002, 36: $1675-168 \mid$

9. Cipriani A, Barbiui C, Geddes JR: Suicide, depression and antidepressants. BMJ 2005, 330:373-374.

10. Hall WD, Mant A, Mitchell PB, Rendle VA, Hickie IB, McManus P. Association between antidepressant prescribing and suicide in Australia, 1991-2000: trend analysis. BM] 2003, 10:1008.

II. Kelly CB, Ansari T, Rafferty T, Stevenson M: Antidepressant prescribing and suicide rate in Northern Ireland. Eur Psychiatry 2003, I 8:325-328.

12. Grunebaum MF, Ellis SP, Li S, Oquendo MA, Mann JJ: Antidepressants and suicide risk in the United States, 1985-1999. / Clin Psychiatry 2004, 65:|456-1462

13. Barak Y, Aizenberg D: Association between antidepressant prescribing and suicide in Israel. Int Clin Psychopharmacol 2006 2I:28I-284.

14. Rahme E, Dasgupta K, Turecki G, Nedjar H, Galbaud du Fort G: Risks of suicide and poisoning among elderly patients prescribed selective serotonin reuptake inhibitors: a retrospective cohort study. J Clin Psychiatry 2008, 69:349-357.

15. Barbui C, Esposito E, Cipriani A: Selective serotonin reuptake inhibitors and risk of suicide: a systematic review of observational studies. CMAJ 2009, I80:29I-297.

16. Juurlink D, Herrmann N, Szalai J, Kopp A, Redelmeier D: Medical IIIness and the Risk of Suicide in the Elderly. Arch Intern Med 2004, 164: I 179-II84.

17. Youssef NA, Rich CL: Does acute treatment with sedatives/ hypnotics for anxiety in depressed patients affect suicide risk? A literature review. Ann Clin Psychiatry 2008, 20:57-169.

18. Barak Y, Olmer A, Aizenberg D: Antidepressants reduce the risk of suicide among elderly depressed patients. Neuropsychopharmacology 2006, 3:178-|8|.

19. Carlsten A, Waern M, Holmgren P, Allebeck P: The role of benzodiazepines in elderly suicides. Scand / Public Health 2003, 3I:224-228.

20. National Corporation of Swedish Pharmacies (Apoteket AB): Sales statistic. Apoteket AB, Stockholm 2006.

21. Waern M, Runeson BS, Allebeck P, Beskow J, Rubenowitz E, Skoog I, Wilhelmsson K: Mental disorder in elderly suicides: a case-control study. Am / Psychiatry 2002, I59:450-455.

22. WHO: The WHO Collaborating Centre for Drug Statistics Methodology. Norwegian Institute of Public Health. WHO Oslo.

23. Voaklander DC, Rowe BH, Dryden DM, Pahal J, Saar P, Kelly KD: Medical illness, medication use and suicide in seniors: a population-based case-control study. J Epidemiol Community Health 2008, 62:138-146

24. Waern M: Alcohol dependence and misuse in elderly suicides. Alcohol Alcohol 2003, 38:249-54.

25. Ben-Porath DD, Taylor SP: The effects of diazepam (valium) and aggressive dispostion on human aggression: an experimental investigation. Addict Behav 2002, 27:167-177.

26. Gunnell D, Middleton N, Frankel S: Method availability and the prevention of suicide - a re-analysis of secular trends in England and Wales 1950-1975. Soc Psychiatry Psychiatr Epidemiol 2000, 35:437-443

27. O'Connell H, Chin A-V, Cunningham C, Lawlor BA: Recent developments: Suicide in older people. BMJ 2004, 329:895-899.

28. Singareddy RK, Balon R: Sleep and suicide in psychiatric patients. Ann Clin Psychiatry 200I, I 3:93-I0I.

29. Valuck RJ, Libby AM, Orton HD, Morrato EH, Allen R, Baldessarini RJ: Spillover Effects on Treatment of Adult Depression in Primary Care After FDA Advisory on Risk of Pediatric Suicidality with SSRIs. Am J Psychiatry 2007, I64: | | 98-1205.

30. Conner KR, Duberstein PR, Conwell $Y$ : The validity of proxybased data in suicide research: a study of patients 50 years of age and older who attempted suicide. I. Psychiatric diagnoses. Acta Psych Scand 200I, 104:204-209.

31. Szanto K, Mulsant BH, Houck PR, Miller MD, Mazumdar S, Reynolds CF 3rd: Treatment outcome in suicidal vs, non-suicidal elderly patients. Am J Geriatr Psychiatry 200I, 9:26I-268.

\section{Pre-publication history}

The pre-publication history for this paper can be accessed here:

http://www.biomedcentral.com/1471-2318/9/20/prepub
Publish with Bio Med Central and every scientist can read your work free of charge

"BioMed Central will be the most significant development for disseminating the results of biomedical research in our lifetime. "

Sir Paul Nurse, Cancer Research UK

Your research papers will be:

- available free of charge to the entire biomedical community

- peer reviewed and published immediately upon acceptance

- cited in PubMed and archived on PubMed Central

- yours - you keep the copyright
BioMedcentral 